\title{
Hepatitis B virus infection status is not associated with poor prognosis in classical Hodgkin lymphoma patients
}

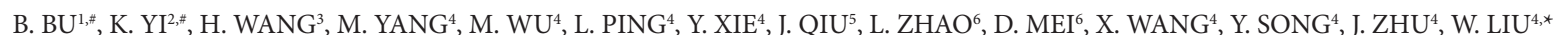

${ }^{1}$ Department of Medical Oncology, Shandong Cancer Hospital affiliated to Shandong University, Shandong University, Jinan, Shandong 250117, China; ${ }^{2}$ Department of Lymphoma and Hematology, Jiangxi Cancer Hospital, Nanchang University, Nanchang, Jiangxi 330006, China; ${ }^{3}$ Department of Pediatric Hematology and Oncology, Shandong Provincial Qianfoshan Hospital, First Hospital Affiliated with Shandong First Medical University, Shandong First Medical University, Jinan, Shandong 250014, China; ${ }^{4}$ Department of Lymphoma, Key Laboratory of Carcinogenesis and Translational Research (Ministry of Education), Peking University Cancer Hospital and Institute, Peking University, Beijing 100142, China; ${ }^{5}$ School of Medicine and Life Sciences, University of Jinan-Shandong Academy of Medical Sciences, Jinan, Shandong 250200, China; ${ }^{6}$ Department of Lymphoma, Peking University International Hospital, Peking University, Beijing 102206, China

${ }^{*}$ Correspondence: dreaming2217@126.com

"Contributed equally to this work.

Received February 11, 2019 / Accepted July 9, 2019

\begin{abstract}
Few studies focused on the relationship between hepatitis B virus (HBV) infection and classical Hodgkin lymphoma (cHL). This study was to evaluate the impact of HBV infection on the treatment outcome and survival of cHL patients. Clinical data of $352 \mathrm{cHL}$ patients treated with ABVD regimen (doxorubicin, bleomycin, vincristine and dacarbazine) between January 2002 and January 2018 were retrospectively collected. According to HBV infection status, the patients were divided into three groups: with HBV infection [hepatitis B surface antigen (HBsAg)-positive], with past HBV infection [HBsAg-negative but anti-hepatitis B core antigen (anti-HBc)-positive], and without HBV infection (HBsAg-negative and anti-HBc-negative). The incidence of HBV infection and past HBV infection in cHL patients were 7.4\% (26/352) and $16.5 \%$ (58/352), respectively. The median age of patients without HBV infection was lower than those in other two groups $(p<0.001)$. The complete remission rates after first-line therapy were different among 3 groups $(65.4 \%$ for the group with HBV infection, $87.9 \%$ for the group with past HBV infection, and $76.1 \%$ for the group without HBV infection, respectively, $\mathrm{p}=0.049$ ). After a median follow-up of 34.6 months, the 3-year progression-free survival rates for the three groups were $69 \%$, $74 \%$ and $80 \%$, respectively $(\mathrm{p}=0.566)$ and the 3 -year overall survival rates were $72 \%, 91 \%$ and $87 \%$, respectively ( $\mathrm{p}=0.096$ ). No HBV reactivation was observed during chemotherapy among 3 groups, but 1 patient in the group with HBV infection experienced delayed HBV reactivation when prophylactic entecavir was discontinued 12 months after the last cycle of chemotherapy. HBV infection status did not affect the clinical outcome and prognosis of cHL patients, especially in the era of prophylactic antiviral therapy.
\end{abstract}

Key words: Hodgkin disease, hepatitis B virus, therapeutics, prognosis

Hepatitis B virus (HBV), a hepatotropic virus, can also infect peripheral blood mononuclear cells and lymph nodes [1]. HBV infection has been found to play a causative role in lymphomagenesis by either chronic antigenic simulation model [2] or antigen-independent mechanism [3]. An epidemiological study involving 603,585 participants showed that hepatitis B surface antigen (HBsAg)-positive participants had an increased risk of non-Hodgkin lymphoma (NHL) overall compared with those who were HBsAg-negative (hazard ratio $=1.74)$. A meta-analysis [4] including 6 studies with a total of 38 Hodgkin lymphoma (HL) cases and 146,087 controls indicated a significantly increased risk of developing $\mathrm{HL}$ in HBV-infected individuals (odds ratio = 1.54).

HBV reactivation during antitumor therapy may lead to fulminant hepatitis, liver failure and death [5], which is related to poor survival. Additionally, HBV infection may confer resistance to chemotherapeutics in lymphoma [6]. Several studies have reported that HBV infection is associated with poor prognosis of patients with NHL, such as NK/T cell lymphoma [7] and diffuse large B-cell lymphoma (DLBCL) [8]. However, little is known about the association of $\mathrm{HBV}$ infection with classic HL (cHL) even in endemic 
area. Importantly, the effect of HBV infection on clinical outcomes of cHL remains unknown.

\section{Patients and methods}

Patients. We searched the database of cancer registries for cases registered from January 2002 to January 2018 with a diagnosis of cHL. To minimize the impact of different chemotherapy regimens, only those patients treated with ABVD regimen (doxorubicin, bleomycin, vincristine and dacarbazine) were included. All clinical information, including demographic findings, clinical presentations, physical examinations, histopathological reports, radiological features and laboratory results, were investigated. All patients in the study were followed up by medical record review until death or the last visit at our institute. The prevalence of HBsAg and hepatitis B core antibody (anti-HBc) in cHL patients was compared with those data from national hepatitis serosurvey conducted by China government [9]. To investigate the relationship between the HBV infection and the clinicopathological characteristics of cHL, we divided cHL patients into three groups according to $\mathrm{HBV}$ infection status: group with HBV infection (HBsAg-positive), group with past $\mathrm{HBV}$ infection (HBsAg-negative but anti-HBc-positive), and group without HBV infection (HBsAg-negative and anti-HBc-negative). This retrospective study was approved by the Ethics Committee at the Peking University Cancer Hospital and Institute and the institutional review boards of the participating centers, in accordance with the Declaration of Helsinki; and the requirement for informed consent was waived because of the anonymous nature of the data.

HBV detection. Enzyme-linked immunosorbent assay (ELISA) was used to determine the HBV infection status, including $\mathrm{HBsAg}$, hepatitis B surface antibody (anti-HBs), hepatitis B e antigen ( $\mathrm{HBeAg}$ ), hepatitis B e antibody (anti$\mathrm{HBe}$ ) and anti-HBc. HBV DNA levels were quantitatively tested by real-time polymerase chain reaction with a low detection limit of $50 \mathrm{IU} / \mathrm{ml}$. HBV DNA was detected at baseline and every 4 weeks, for at least one year after completion of chemotherapy.

Definition of HBV reactivation. Based on a previous study [10], HBV reactivation was defined as a marked increase in HBV replication ( $\geq 2 \log 10$ increase from baseline levels or a new appearance of HBV DNA to a level of $\geq 100 \mathrm{IU} / \mathrm{ml}$ ) in a person with previously stable or undetectable levels. The reactivation of past $\mathrm{HBV}$ infection was defined as $\mathrm{HBsAg}$ reverse seroconversion (reappearance of $\mathrm{HBsAg}$ ), or appearance of HBV DNA in serum in the absence of HBsAg.

Follow up. In the study, the follow-up period began at the date of cHL diagnosis and ended at the date of death or June 1st, 2018. Progression-free survival (PFS) was calculated from the time of diagnosis to progression, relapse, death or the end of the follow-up period; and overall survival (OS) was calculated from the time of diagnosis to death or the end of the follow-up period.
Statistical analysis. All statistical analyses were performed with the IBM SPSS Statistics for windows (Version 21.0; IBM Corp., New York, USA). Categorical variables were compared using Pearson $\chi^{2}$ analysis or Fisher's exact test. Continuous variables were compared using the t-test. Kaplan-Meier curves were used to compare the differences in PFS and OS among the groups, and the log-rank Chi-square test was used to calculate the significance of the differences. Multivariate Cox proportional hazards analysis was performed to determine the effects of the variables on survival. All statistical tests were two-tailed, and $\mathrm{p}<0.05$ was considered statistically significant.

\section{Results}

Baseline characteristics. A total of 424 patients with cHL were reviewed, and 72 patients were excluded. Finally, 352 patients were analyzed in the study, including 207 males and 145 females. The median age of the patients at diagnosis of cHL was 32 years. Nodular sclerosis cHL was the most frequent pathological type, followed by mixed cellularity cHL, lymphocyte-rich cHL and lymphocyte-depleted cHL.

HBV infection was documented in $26(7.4 \%)$ patients at diagnosis of cHL, and past HBV infection was in 58 (16.5\%) patients. The prevalence of HBsAg in cHL patients was similar to that of general population $(7.4 \%$ vs. $7.2 \%, p=0.881)$, but the prevalence of anti-HBc was significantly lower $(23.9 \%$ vs. $34.1 \%, \mathrm{p}<0.001)$. In addition, $43(74.1 \%)$ patients had positive anti-HBs in the group with past HBV infection.

The group without HBV infection was younger than the other two groups. Higher proportion of absolute platelet count $<100 \times 10^{9} / \mathrm{L}$ was observed in the group with HBV infection (Table 1). There was no other significant difference in clinicopathological characteristics among 3 groups. In the group with HBV infection, baseline HBV DNA was detectable in 15 patients with a median titer of $5.58 \times 10^{4}$ (range, $\left.1.24 \times 10^{2}-4.59 \times 10^{8}\right) \mathrm{IU} / \mathrm{mL}$. Only 1 patient had mildly elevated alanineaminotransferase (ALT) prior to chemotherapy. Prophylactic antiviral therapy was administrated in all 26 patients, of which entecavir was used in 15 patients, lamivudine in 7 , adefovir dipivoxil in 3 and telbivudine in 1 . In the group with past HBV infection, all 58 patients had undetectable HBV DNA at baseline and only 3 patients received prophylactic antiviral therapy ( 2 with entecavir and 1 with lamivudine). Prophylactic antiviral therapy continued until at least 12 months after last chemotherapy in the group of HBV infection and 6 months after last chemotherapy in the group of past $\mathrm{HBV}$ infection.

Response to antitumor therapy. A total of 2,187 cycles of chemotherapy with ABVD regimen were administered (median, 6 cycles/patient; range, 2-8 cycles). After the firstline chemotherapy, 78 patients received radiotherapy, and 5 patients underwent autologous hematopoietic stem cell transplantation. The objective response rate (ORR) for all patients was $90.7 \%$ (319/352), with a complete remission (CR) rate of 
Table 1. Comparison of clinicopatological characteristics among patients according to HBV infection status.

\begin{tabular}{|c|c|c|c|c|c|}
\hline & $\begin{array}{l}\text { All patients } \\
(\mathrm{n}=352)\end{array}$ & $\begin{array}{l}\text { Group with HBV } \\
\text { infection }(n=26)\end{array}$ & $\begin{array}{c}\text { Group with past HBV } \\
\text { infection }(n=58)\end{array}$ & $\begin{array}{l}\text { Group without HBV } \\
\text { infection }(n=268)\end{array}$ & p-value \\
\hline Age (mean $\pm S D$, years) & $36.0 \pm 15.5$ & $43.6 \pm 15.4$ & $44.3 \pm 14.3$ & $33.5 \pm 14.9$ & $<0.001$ \\
\hline$>60$ years & $27(7.7 \%)$ & $3(11.5 \%)$ & $7(12.1 \%)$ & $17(6.3 \%)$ & 0.247 \\
\hline Sex & & & & & 0.125 \\
\hline Male & $207(58.8 \%)$ & $19(73.1 \%)$ & $38(65.5 \%)$ & $150(56.0 \%)$ & \\
\hline Female & $145(41.2 \%)$ & $7(26.9 \%)$ & $20(34.5 \%)$ & $118(44.0 \%)$ & \\
\hline Pathologic type & & & & & 0.165 \\
\hline LR & $20(5.7 \%)$ & $2(7.7 \%)$ & $3(5.2 \%)$ & $15(5.6 \%)$ & \\
\hline NS & $207(58.8 \%)$ & $12(46.2 \%)$ & $28(48.3 \%)$ & $167(62.3 \%)$ & \\
\hline $\mathrm{MC}$ & $111(31.5 \%)$ & $11(42.3 \%)$ & $25(43.1 \%)$ & $75(28.0 \%)$ & \\
\hline $\mathrm{LD}$ & $2(0.6 \%)$ & $1(3.8 \%)$ & $0(0)$ & $1(0.4 \%)$ & \\
\hline unclassified & $12(3.4 \%)$ & $0(0)$ & $2(3.4 \%)$ & $10(3.7 \%)$ & \\
\hline ECOG performance & & & & & 0.246 \\
\hline Score $0-1$ & $349(99.1 \%)$ & $25(96.2 \%)$ & $57(98.3 \%)$ & $267(99.6 \%)$ & \\
\hline Score $2-4$ & $3(0.9 \%)$ & $1(3.8 \%)$ & $1(1.7 \%)$ & $1(0.4 \%)$ & \\
\hline Stage & & & & & 0.127 \\
\hline $1-2$ & $211(59.9 \%)$ & $11(42.3 \%)$ & $33(56.9 \%)$ & $167(62.3 \%)$ & \\
\hline $3-4$ & $141(40.1 \%)$ & $15(57.7 \%)$ & $25(43.1 \%)$ & $101(37.7 \%)$ & \\
\hline B symptom & $103(29.3 \%)$ & $8(30.8 \%)$ & $20(34.5 \%)$ & $75(28.0 \%)$ & 0.612 \\
\hline Extra-nodal involvement & $88(25.1 \%)$ & $6(23.1 \%)$ & $15(25.9 \%)$ & $67(25.1 \%)$ & 0.963 \\
\hline $\mathrm{WBC}>10 \times 10^{9} / \mathrm{L}$ & $101(28.7 \%)$ & $5(19.2 \%)$ & $15(25.9 \%)$ & $81(30.2 \%)$ & 0.413 \\
\hline $\mathrm{ALC}<1 \times 10^{9} / \mathrm{L}$ & $76(21.6 \%)$ & $7(26.9 \%)$ & $15(25.9 \%)$ & $54(20.1 \%)$ & 0.510 \\
\hline Anemia & $68(19.3 \%)$ & $5(19.2 \%)$ & $12(20.7 \%)$ & $51(19.0 \%)$ & 0.959 \\
\hline $\mathrm{PLT}<100 \times 10^{9} / \mathrm{L}$ & $9(2.6 \%)$ & $3(11.5 \%)$ & $0(0)$ & $6(2.2 \%)$ & 0.021 \\
\hline $\mathrm{ALB}<35 \mathrm{~g} / \mathrm{L}$ & $28(8.0 \%)$ & $4(15.4 \%)$ & $5(8.6 \%)$ & $19(7.1 \%)$ & 0.388 \\
\hline Elevated LDH & $87(24.7 \%)$ & $9(34.6 \%)$ & $15(25.9 \%)$ & $63(23.5 \%)$ & 0.467 \\
\hline
\end{tabular}

${ }^{*}$ p-value refers to the difference among three groups; ALB, albumin; ALC, absolute lymphocyte count; ECOG, Eastern Cooperative Oncology Group; LD, lymphocyte-depleted classical Hodgkin lymphoma; LDH, lactate dehydrogenase; LR, lymphocyte-rich classical Hodgkin lymphoma; MC, mixed cellularity classical Hodgkin lymphoma; NS, nodular sclerosis classical Hodgkin lymphoma; PLT, platelet; SD, standard deviation; WBC, white blood cell

Table 2. Comparison of treatment modality and effectiveness among patients according to HBV infection status.

\begin{tabular}{|c|c|c|c|c|c|}
\hline & $\begin{array}{l}\text { All patients } \\
\qquad(\mathrm{n}=352)\end{array}$ & $\begin{array}{l}\text { Group with HBV } \\
\text { infection }(n=26)\end{array}$ & $\begin{array}{l}\text { Group with past HBV } \\
\text { infection }(n=58)\end{array}$ & $\begin{array}{l}\text { Group without HBV } \\
\text { infection }(n=268)\end{array}$ & p-value ${ }^{*}$ \\
\hline Median cycles of chemotherapy & $6(2-8)$ & $6(4-8)$ & $6(2-8)$ & $6(2-8)$ & 0.603 \\
\hline Radiotherapy & $78(22.2 \%)$ & $7(26.9 \%)$ & $7(12.1 \%)$ & $64(23.9 \%)$ & 0.121 \\
\hline AHSCT & $5(1.4 \%)$ & $0(0)$ & $1(1.7 \%)$ & $4(1.5 \%)$ & 0.824 \\
\hline Response to antitumor therapy & & & & & 0.212 \\
\hline $\mathrm{CR}$ & $272(77.3 \%)$ & $17(65.4 \%)$ & $51(87.9 \%)$ & $204(76.1 \%)$ & \\
\hline PR & $47(13.4 \%)$ & $5(19.2 \%)$ & $3(5.2 \%)$ & $39(14.6 \%)$ & \\
\hline $\mathrm{SD}$ & $10(2.8 \%)$ & $1(3.8 \%)$ & $0(0)$ & $9(3.4 \%)$ & \\
\hline $\mathrm{PD}$ & $23(6.5 \%)$ & $3(11.5 \%)$ & $4(6.9 \%)$ & $16(6.0 \%)$ & \\
\hline
\end{tabular}

${ }^{*}$ p-value refers to the difference among three groups; AHSCT, autologous hematopoietic stem cell transplantation; CR, Complete Remission; PD, progression disease; PR, partial remission; $\mathrm{SD}$, stable disease

$77.3 \%$ and a partial remission (PR) rate of $13.4 \%$ (Table 2). The ORR and CR rates were $84.6 \%$ and $65.4 \%$ for the group with HBV infection, $93.1 \%$ and $87.9 \%$ for the group with past HBV infection, $90.7 \%$ and $76.1 \%$ for the group without HBV infection, respectively. No disruption of chemotherapy due to adverse effects of antiviral therapy was observed.

HBV reactivation in cHL patients. In the group with HBV infection, no HBV reactivation was observed during chemotherapy. However, one patient experienced delayed HBV reactivation after withdrawal of antiviral therapy. This 27-year-old male patient discontinued prophylactic entecavir 12 months after the last cycle of chemotherapy. Five months later, HBV reactivation was diagnosed because HBV DNA titer increased from undetectable levels to $1.28 \times 10^{7} \mathrm{IU} / \mathrm{ml}$, and ALT increased from normal levels to $195 \mathrm{IU} / \mathrm{ml}$. He recovered from HBV-related hepatitis after re-administration 
of antiviral therapy with entecavir. The other 25 patients did not stop antiviral therapy until the end of follow-up period with a median duration of 34.2 (range, 14.1-86.1) months, and none experienced $\mathrm{HBV}$ reactivation.

While in the group with past HBV infection, only 3 patients received antiviral prophylaxis, and discontinued 6 months after the last cycle of chemotherapy. None of these 58 patients experienced HBV reactivation regardless of whether prophylactic antiviral therapy was administrated or not.

Survival rate and prognostic factors. After a median follow-up period of 34.2 months, 56 patients had disease progression, 6 of which were in the group with HBV infection, 11 in the group with past HBV infection, and 39 in the group without HBV infection. The expected 3-year PFS rates for the three groups were $69 \%, 80 \%$ and $74 \%$, respectively $(\mathrm{p}=0.566$, Figure 1$)$.

Twenty-three patients died, 5 of which were in the group with HBV infection, 3 in the group with past HBV infection, and 15 in the group without HBV infection. The 3-year OS rates for the three groups were $72 \%, 91 \%$ and $87 \%$, respectively ( $\mathrm{p}=0.096$, Figure 2 ).

In univariate analysis, age $>60$ years, $\mathrm{B}$ symptom, extranodal involvement, lower absolute lymphocyte count $\left(<1 \times 10^{9} / 1\right)$, anemia, lower platelet count $\left(<100 \times 10^{9} / 1\right)$, lower albumin level $(<35 \mathrm{~g} / \mathrm{l})$ and elevated lactate dehydrogenase were poor risk factors for OS (Table 3). Notably, HBV infection status was not a risk factor for OS in Cox analysis $(\mathrm{p}=0.506)$. Multivariate analysis indicated that age $>60$ years and anemia were independent poor predictors of OS.

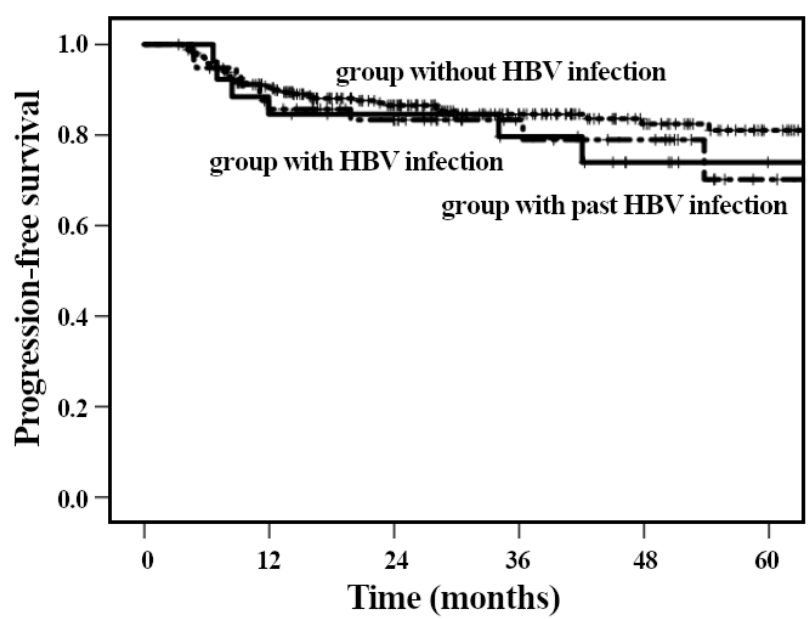

Figure 1. Comparison of progression-free survival according to HBV infection status $(\mathrm{p}=0.566)$

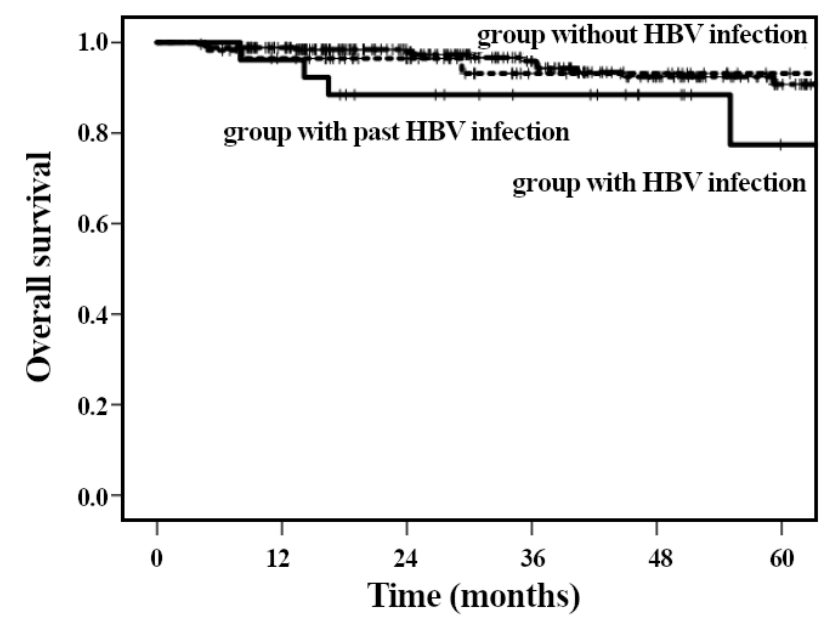

Figure 2. Comparison of overall survival according to $\mathrm{HBV}$ infection status $(\mathrm{p}=0.096)$

Table 3. Analysis of risk factors for overall survival.

\begin{tabular}{|c|c|c|c|c|c|c|}
\hline & \multicolumn{3}{|c|}{ Univariate analysis } & \multicolumn{3}{|c|}{ Multivariate analysis } \\
\hline & Hazard ratio & $95 \% \mathrm{CI}$ & p-value & Hazard ratio & $95 \% \mathrm{CI}$ & p-value \\
\hline Age $>60$ years & 9.502 & $4.117-21.933$ & $<0.001$ & 8.613 & $3.694-20.085$ & $<0.001$ \\
\hline Sex & 0.787 & $0.347-1.787$ & 0.567 & & & \\
\hline Pathologic type & 1.190 & $0.796-1.779$ & 0.396 & & & \\
\hline ECOG performance & 1.422 & $0.632-3.201$ & 0.394 & & & \\
\hline Stage & 1.859 & $0.817-4.227$ & 0.139 & & & \\
\hline B symptom & 2.878 & $1.268-6.530$ & 0.011 & & & \\
\hline Extra-nodal involvement & 3.025 & $1.319-6.941$ & 0.009 & & & \\
\hline $\mathrm{WBC}>10 \times 10^{9} / \mathrm{L}$ & 0.370 & $0.110-1.245$ & 0.108 & & & \\
\hline $\mathrm{ALC}<1 \times 10^{9} / \mathrm{L}$ & 3.196 & $1.366-7.477$ & 0.007 & & & \\
\hline Anemia & 3.709 & $1.572-8.748$ & 0.003 & 3.032 & $1.287-7.144$ & 0.011 \\
\hline PLT $<100 \times 10^{9} / \mathrm{L}$ & 8.264 & $2.777-24.595$ & $<0.001$ & & & \\
\hline $\mathrm{ALB}<35 \mathrm{~g} / \mathrm{L}$ & 3.849 & $1.414-10.472$ & 0.008 & & & \\
\hline Elevated LDH & 2.648 & $1.158-6.054$ & 0.021 & & & \\
\hline HBV infection status & 1.192 & $0.711-1.998$ & 0.506 & & & \\
\hline
\end{tabular}

ALB, albumin; ALC, absolute lymphocyte count; ECOG, Eastern Cooperative Oncology Group; HBV, hepatitis B virus; LDH, lactate dehydrogenase; PLT, platelet; WBC, white blood cell 


\section{Discussion}

The prevalence of HBV infection is different between HL and NHL. A study [8] from an HBV endemic area demonstrated that HBsAg prevalence in DLBCL patients was significantly higher than that in general population $(23.6 \%$ vs. $7.2 \%, \mathrm{p}<0.001$ ), which is consistent with the results of 405 NHL patients in our previous report [11]. A study [12] involving $120 \mathrm{HL}$ patients indicated that HBsAg prevalence was similar between HL patients and general population. In our study, compared with general population, $\mathrm{cHL}$ patients had similar HBsAg prevalence and lower anti-HBc prevalence, which may be due to routine childhood immunization in China [13] and domination of younger people in $\mathrm{HL}$ patients [14]. These findings suggested HBV infection may be not a pathogenesis factor for cHL.

Prophylactic antiviral therapy has been recommended for HBsAg-positive patients to prevent $\mathrm{HBV}$ reactivation by clinical practice guidelines [15-18]. In our study, all 26 HBsAg-positive patients received prophylactic antiviral therapy, and none experienced HBV reactivation during chemotherapy. This finding is in agreement with the recommendations in clinical practice guidelines. Of note was that delayed HBV reactivation after withdrawal of prophylactic agents may be a problem. In our previous study [19], the incidence of delayed $\mathrm{HBV}$ reactivation and HBV-related hepatitis flares after withdrawal of prophylactic antiviral therapy in $46 \mathrm{HBsAg}$-positive patients with DLBCL was $21.7 \%$ and $10.9 \%$, respectively. In the present study, one $\mathrm{HBsAg}$-positive patient experienced delayed HBV reactivation after he discontinued the prophylactic agent even 12 months after the last cycle of chemotherapy. The median duration of prophylactic antiviral therapy in the other 15 HBsAg-positive patients was 34.2 months. Therefore, large prospective investigations need to be conducted to understand whether long-term use of antiviral therapy can be avoided for HBsAg-positive patients after the end of chemotherapy.

There is a concern about antiviral prophylaxis and HBV reactivation in patients with past $\mathrm{HBV}$ infection. A technical review [20] from American Gastroenterological Association Institute revealed that the mean frequency of $\mathrm{HBV}$ reactivation was $12.2 \%$ in 401 lymphoma patients with past $\mathrm{HBV}$ infection who were not given prophylactic antiviral therapy, and rituximab increased the risk of $\mathrm{HBV}$ reactivation. Those patients with past $\mathrm{HBV}$ infection receiving anthracyclinebased regimens without rituximab were classified as the moderate-risk group with anticipated incidence of $\mathrm{HBV}$ reactivation of $1 \%$ to $10 \%$ [17]. In our study, $58(16.5 \%)$ patients had past HBV infection, only 3 of whom received antiviral prophylaxis. None experienced HBV reactivation regardless of whether they received antiviral therapy. This finding suggested that no antiviral prophylaxis may be a reasonable choice for $\mathrm{CHL}$ patients treated with ABVD regimen when cost-effectiveness was considered.
Controversy remains concerning the effect of HBV infection on the outcomes of lymphoma patients. A study [8] involving 508 DLBCL patients showed that HBV infection had a negative effect on therapeutic outcomes with an odds ratio of 3.04, whereas another study [21] demonstrated that there was no significant difference in CR rate and OS between HBsAg-positive DLBCL group and HBsAg-negative DLBCL group. However, few study addressed this question in HL patients. Among the three groups in our study, the difference in response rates had no statistical significance. It is worth mentioning that there is no statistical difference in PFS and OS among three groups and HBV infection status was not a risk factor for OS in COX analysis. These results indicated that the status of HBV infection could not be a key factor influencing the prognosis of cHL patients after chemotherapy with ABVD regimen.

The interpretation of our study has several limitations. First, the small sample size in group with HBV infection due to the decreasing prevalence of HBV [9] and low burden of lymphoma in China [22, 23], should be taken into account when the clinical significance of statistic difference in response rates were evaluated. Second, the effect of HBV infection on prognosis may be weakened in HL patients because of good response to chemotherapy with ABVD regimen. Third, the follow-up period was variable due to death from lymphoma progression, which should also be considered. Finally, the correlation between $\mathrm{HBV}$ reactivation and salvage treatment was not evaluated due to the heterogeneity of regimens.

In conclusion, $\mathrm{HBV}$ infection and past $\mathrm{HBV}$ infection are not rare in $\mathrm{cHL}$ patients resided in $\mathrm{HBV}$ endemic areas. Prophylactic antiviral therapy should be administrated for those HBsAg-positive patients and may be an optional choice for those patients with past HBV infection. Both HBV infection and past $\mathrm{HBV}$ infection did not have negative effect on the prognosis of cHL, especially in the era of prophylactic antiviral therapy.

Acknowledgements: This research was supported by the Capital's Funds for Health Improvement and Research (Grant No. 2018-12151).

\section{References}

[1] JOSHI SS, COFFIN CS. Hepatitis B virus lymphotropism: emerging details and challenges. Biotechnol Genet Eng Rev 2018; 34: 139-151. https://doi.org/10.1080/02648725.2018.1 474324

[2] BO J, WANG X, LI J, WANG W, ZHANG J. Consecutive stimulation of HBsAg promotes the viability of the human $B$ lymphoblastoid cell line IM-9 through regulating the SIRT1NF-kB pathway. Oncol Lett 2017; 14: 433-440. https://doi. org/10.3892/ol.2017.6114

[3] REN W, YE X, SU H, LI W, LIU D et al. Genetic landscape of hepatitis B virus-associated diffuse large B-cell lymphoma. Blood 2018; 131: 2670-2681. https://doi.org/10.1182/ blood-2017-11-817601 
[4] DALIA S, DUNKER K, SOKOL L, MHASKAR R. Hepatitis B seropositivity and risk of developing multiple myeloma or Hodgkin lymphoma: A meta-analysis of observational studies. Leuk Res 2015; 39: 1325-1333. https://doi.org/10.1016/j. leukres.2015.09.008

[5] CHOI J, LIM YS. Characteristics, Prevention, and Management of Hepatitis B Virus (HBV) Reactivation in HBV-Infected Patients Who Require Immunosuppressive Therapy. J Infect Dis 2017; 216(suppl_8): S778-S784. https://doi. org/10.1093/infdis/jix178

[6] ZHAO X, GUO X, XING L, YUE W, YIN H et al. HBV infection potentiates resistance to $\mathrm{S}$-phase arrest-inducing chemotherapeutics by inhibiting CHK2 pathway in diffuse large B-cell lymphoma. Cell Death Dis 2018; 9: 61. https:// doi.org/10.1038/s41419-017-0097-1

[7] WANG K, YANG H, HE W, XIA Y, XIA Z et al. Association between extranodal natural killer/T-cell lymphoma and hepatitis B viral infection: a case-control study. J Cancer 2017; 8: 2676-2683. https://doi.org/10.7150/jca.19665

[8] WANG Y, WANG H, PAN S, HU T, SHEN J et al. Capable Infection of Hepatitis B Virus in Diffuse Large B-cell Lymphoma. J Cancer 2018; 9: 1575-1581. https://doi.org/10.7150/ jca. 24384

[9] LIANG X, BI S, YANG W, WANG L, CUI G et al. Epidemiological serosurvey of hepatitis B in China--declining HBV prevalence due to hepatitis B vaccination. Vaccine 2009; 27: 6550-6557. https://doi.org/10.1016/j.vaccine.2009.08.048

[10] HWANG JP, LOK AS. Management of patients with hepatitis B who require immunosuppressive therapy. Nat Rev Gastroenterol Hepatol 2014; 11: 209-219. https://doi.org/10.1038/ nrgastro.2013.216

[11] LIU WP, ZHENG W, WANG XP, SONG YQ, XIE Y et al. [An analysis of hepatitis $B$ virus infection rate in 405 cases of non-Hodgkin lymphoma.] Zhonghua Xue Ye Xue Za Zhi 2011; 32: 521-524 https://doi.org/10.3760/cma.j.is sn.0253-2727.2011.08.006

[12] QIU MZ, RUAN DY, WANG ZQ, LUO HY, TENG KY et al. The expression of hepatitis $B$ virus surface antigen in 120 Hodgkin's lymphoma patients. Chin J Cancer 2010; 29: 735740. https://doi.org/10.5732/cjc.010.10038

[13] CUI F, SHEN L, LI L, WANG H, WANG F et al. Prevention of Chronic Hepatitis B after 3 Decades of Escalating Vaccination Policy, China. Emerg Infect Dis 2017; 23: 765-772. https://doi.org/10.3201/eid2305.161477
[14] FLERLAGE JE, METZGER ML, BHAKTA N. The management of Hodgkin lymphoma in adolescents and young adults: burden of disease or burden of choice? Blood 2018; 132: 376384. https://doi.org/10.1182/blood-2018-01-778548

[15] EUROPEAN ASSOCIATION FOR THE STUDY OF THE LIVER. EASL 2017 Clinical Practice Guidelines on the management of hepatitis B virus infection. J Hepatol 2017; 67: 370-398. https://doi.org/10.1016/j.jhep.2017.03.021

[16] LOK AS, MCMAHON BJ. Chronic hepatitis B: update 2009. Hepatology 2009; 50: 661-662. https://doi.org/10.1002/ hep. 23190

[17] REDDY KR, BEAVERS KL, HAMMOND SP, LIM JK, FALCK-YTTER et al. American Gastroenterological Association Institute guideline on the prevention and treatment of hepatitis $\mathrm{B}$ virus reactivation during immunosuppressive drug therapy. Gastroenterology 2015; 148: 215-219; quiz e16-7. https://doi.org/10.1053/j.gastro.2014.10.039

[18] HWANG JP, SOMERFIELD MR, ALSTON-JOHNSON DE, CRYER DR, FELD JJ et al. Hepatitis B Virus Screening for Patients With Cancer Before Therapy: American Society of Clinical Oncology Provisional Clinical Opinion Update. J Clin Oncol 2015; 33: 2212-2220. https://doi.org/10.1200/ JCO.2015.61.3745

[19] LIU WP, WANG XP, ZHENG W, PING LY, ZHANG C et al. Hepatitis $B$ virus reactivation after withdrawal of prophylactic antiviral therapy in patients with diffuse large B cell lymphoma. Leuk Lymphoma 2016; 57: 1355-1362. https:// doi.org/10.3109/10428194.2015.1116121

[20] PERRILLO RP, GISH R, FALCK-YTTER YT. American Gastroenterological Association Institute technical review on prevention and treatment of hepatitis B virus reactivation during immunosuppressive drug therapy. Gastroenterology 2015; 148: 221-244. https://doi.org/10.1053/j.gastro.2014.10.038

[21] LAW MF, LAI HK, CHAN HN, HA CY, NG C et al. The impact of hepatitis $B$ virus (HBV) infection on clinical outcomes of patients with diffuse large B-cell lymphoma. Eur J Cancer Care (Engl) 2015; 24: 117-124. https://doi. org/10.1111/ecc.12166

[22] LIU W, LIU J, SONG Y, WANG X, ZHOU M, et al. Mortality of lymphoma and myeloma in China, 2004-2017: an observational study. J Hematol Oncol 2019; 12: 22. https://doi: 10.1186/s13045-019-0706-9

[23] LIU W, LIU J, SONG Y, ZENG X, WANG X et al. Burden of lymphoma in China, 2006-2016: an analysis of the Global Burden of Disease Study 2016. J Hematol Oncol. 2019; 12: 115. https://doi.org/10.1186/s13045-019-0785-7 